\title{
ENSAYO/ESSAY
}

\section{MARTÍ, PROPAGANDISTA}

Francisco Marín Calahorro': Oficina de Relaciones Informativas de Defensa. España.

fmarincalahorro@hotmail.com

\section{RESUMEN}

José Martí nace como escritor porque con la palabra expresa su rechazo al dominio español en Cuba. Con la propaganda por medio del periódico orienta la opinión de los cubanos y los une para luchar por la independencia. De hecho, sus primeros pasos literarios son simultáneos con su inicio en la política revolucionaria. Entre sus actividades literarias predomina su actividad periodística representada por el artículo político con tintes propagandísticos. Según el público al que se dirija, su discurso debe ser único y reiterado. Así abre tres frentes: uno dirigido a los cubanos, otro a los españoles y otro a los actores internacionales. $Y$ utiliza dos tipos de propaganda: de Consolidación, para mantener y reforzar actitudes existentes, y de Conversión, para atraer a los neutrales y amigos. A su muerte, nadie será capaz de sustituir a Martí en su labor de propaganda.

PALABRAS CLAVE: José Martí - Propaganda - Independencia - Cuba - España.

\footnotetext{
${ }^{1}$ Autor correspondiente:

Francisco Marín Calahorro: Coronel de Caballería en Oficina de Relaciones Informativas de Defensa. España.

Correo: fmarincalahorro@hotmail.com
} 


\section{MARTI, PROMOTER}

\section{ABSTRACT}

José Martí was born as a writer because the word expresses its rejection of Spanish rule in Cuba. With newspaper advertising through the view orientation and unites Cubans to fight for independence. In fact, his first literary steps are simultaneous with its inception in revolutionary politics. Among his literary activities dominates his journalism represented by propaganda tinged political article. According to the audience it is directed, his speech must be unique and reiterated. It opens three fronts: one directed to the Cubans, one at the Spanish and other international actors. And uses two types of advertising: Consolidation, to maintain and reinforce existing attitudes and Conversion, to attract neutrals and friends. At his death, no one will be able to replace Marti in their propaganda.

KEYWORDS: Jose Marti - Propaganda - Independence - Cuba - Spain.

\section{INTRODUCCIÓN}

Martí es un propagandista nato, difícil de separar de su imagen de escritor y político. Nace como escritor porque precisa el instrumento verbal que le permita exponer su rechazo al dominio español en Cuba. Comprende, como Napoleón un siglo antes, que la propaganda por medio del periódico y la tribuna es indispensable para orientar la opinión de los cubanos en el destierro y lograr la unión de todos ellos para la lucha por la independencia.

Sus primeros pasos literarios son simultáneos con su inicio en la política revolucionaria. A los dieciséis años dirige un periódico escolar, La Patria Libre, en donde, bajo la alegoría de un imaginario país africano y su héroe Abdala De Nubla, glosa la libertad de Cuba. No se limita a las palabras y pasa a la acción. Acompaña a su maestro Mendive en los actos de protesta de enero de 1869 y participa en el agravio al Cuerpo de Voluntarios. Hecho que motiva su proceso y condena a trabajos forzados en el presidio de La Cabaña y su posterior deportación a la Metrópoli.

Lo que ve y le sucede allí troquela en Martí su estereotipo "España", que reflejará en el folleto El Presidio Político en Cuba, publicado en 1871 durante su estancia en la Península. Su contenido no se puede contemplar como obra de propaganda, sino como un alegato judicial en contra de los abusos de "todos aquellos míseros que, a la par que las espaldas del cautivo, despedazan el honor y la dignidad de su nación". Reacción emocional que produce un doble efecto: la exaltación de Cuba y su rechazo hacia España.

Efecto que se reflejará en sus esfuerzos para atraer a su causa las simpatías de otras naciones, restándoselas a España. Los soportes de su argumentación son la profanación por el gobierno español de los preceptos cristianos y la invocación 
emotiva de los derechos a la vida, a la libertad y a la felicidad, derechos naturales proclamados por las revoluciones norteamericana y francesa.

Martí cuando escribe predica. La literatura es su medio para realizar la parte más importante de su acción libertadora y las formas que utilizó para llegar a los públicos, periodismo, la oratoria y el género epistolar, buscaron, a través de una comunicación inmediata y ágil, destinatarios en quienes sus ideas tuvieran rápido eco. Así, a medida que progresa en su dedicación a la causa revolucionaria, predomina, sobre otras actividades literarias, su actividad periodística representada en muchas ocasiones por el artículo político con tintes propagandísticos.

A Martí se le oye al leerlo. Su estilo es coloquial y, como afirma Gerardo Gastellanos, con "su palabra fácil gana sectarios y voluntades que le obedecían ciegamente". Pretende crear una rebelión apoyada en las palabras. Para ello funda, el 14 de marzo de 1892, el semanario Patria, del que será director, redactor, colaborador y, en ocasiones, corrector. Lo que le permite estar en contacto personal con los adherentes al Partido Revolucionario Cubano, creado poco antes, y con los clubs que lo integraban. Casi todo el contenido del periódico muestra el esfuerzo propagandístico en el proceso de preparación para la guerra, sobre todo para la guerra de convicciones.

\section{JUSTIFICAR LA GUERRA}

Justificar ante todos- cubanos, españoles, ante otras naciones, en particular las naciones y pueblos de América- que la guerra que prepara es una guerra justa e inevitable será uno de los ejes permanentes de la acción propagandística de Martí.

Acción que desarrollará desde tres ángulos de visión distintos, pero coincidentes: la justificación moral e histórica de la guerra, la aclaración de que los móviles que la preparan se dirigen al bien público y a la dignificación de la patria y el pueblo cubano y, por último, la defensa de la capacidad de los cubanos para gobernar Cuba y la incapacidad de España para hacerlo.

Por ello, desde el primer momento, plantea con claridad la cuestión de la guerra debidamente justificada, admitida como mal irremediable para evitar males mayores. Así, en la primera declaración oficial del Partido Revolucionario Cubano, el 14 de marzo de 1892, parafraseando a Clausewitz reconoce que "... la guerra es un procedimiento político y este procedimiento de la guerra es conveniente en Cuba" y añade que "... una de las razones fundamentales de la guerra civil en Cuba es que representa la voluntad unánime de los verdaderos cubanos y de los españoles ecuánimes".

Acude a todas las razones morales, de derecho natural y de filosofía política para convalidar la guerra. "... ellos saben que ésta que se levanta es una guerra nacida de la rebelión del hombre contra todo lo que aje una dignidad o merme un derecho humano", afirma en Patria el 14 de marzo de 1893. Obsesión que le acompañará antes y después de comenzar la definitiva Guerra Libertadora. Razón por la que dedica 
una parte importante del Manifiesto de Montecristi, previo al alzamiento, a justificar la guerra. Como señala Guy Pérez Cisneros: "el Manifiesto de Montecristi no es más que el esfuerzo de un hombre de paz para lograr la definición, pincelada por pincelada de lo que pudiera ser una guerra justa".

Esfuerzo en el que no ceja ni siquiera durante su presencia en los campos de Cuba días antes de su muerte. Así, por última vez, explica los móviles de la guerra a George E. Bryson, corresponsal del New York Herald, en la visita que éste le hizo los días 2 y 3 de mayo de 1895. Durante ella Martí redacta una carta-manifiesto "Al New York Herald", en términos similares al Manifiesto de Montecristi, para justificar que "Cuba se ha levantado en armas, con el júbilo del sacrificio y la solemne determinación de la muerte (...) para emancipar a un pueblo inteligente y generoso, de espíritu universal y con deberes especiales en América, de la nación española, inferior a Cuba en la aptitud para el trabajo moderno y el gobierno libre..."

\section{FRENTES DE PROPAGANDA}

El instinto propagandista de Martí, como ocurría en Napoleón, le dice que la propaganda es labor de uno sólo, y entiende, como maestro que ha sido que, para cada público al que se dirija, el discurso debe ser único y reiterado. Así, desde el primer momento, abre tres frentes para la acción, uno dirigido a los cubanos, otro a los españoles y un tercero hacia los actores internacionales.

Es consciente que la única forma de ganar la guerra es aunar voluntades para la acción conjunta. Por ello, atraer y unir a los cubanos de cualquier clase o raza, estén en la Isla o emigrados, será el objetivo de la propaganda dirigida al primer frente. Así, en Las Bases del Partido Revolucionario Cubano, dice que se "ha de procurar el conocimiento de todos los que estén dispuestos a la obra revolucionaria y la conversión de todo los que se le opongan; ha de congregar (...) los elementos dispersos y hostiles entre sí".

Propaganda de Consolidación, para mantener y reforzar actitudes existentes, y Propaganda de Conversión para atraer a los neutrales y amigos. No quiere que reaparezcan las causas que dieron al traste con la ilusión de la Guerra Grande. En ella la suerte de las armas habla sido adversa a los independentistas no sólo por razones técnicas, militares o por falta de recursos efectivos, sino por divisiones y desorganización interna y por falta de unidad en el Estado Mayor revolucionario. La unión de todos es esencial para el triunfo en, la que Martí considera, la continuación de la Guerra Grande; así lo especifica en la Circular dirigida el 3 de septiembre de 1892 a los Presidentes de las Asociaciones y de los Cuerpos del Consejo del Partido Revolucionario Cubano: "que continuamos la revolución para bien de la Isla y de todos sus habitantes, (...) y no para satisfacción parcial de un grupo de cubanos hostil a los demás grupos, ni para servir pensamiento personal alguno".

Desde 1887, cuando ya medita organizar científicamente la invasión de Cuba, Martí siente la necesidad apremiante de crear un núcleo que aglutine los ideales de libertad e independencia, y mantiene la tesis de que no puede llevarse a cabo la Revolución 
sin apoyarse en un partido político que la fundamente jurídicamente y unifique las diversas tendencias, pues los movimientos anteriores fueron considerados como bandas de ciudadanos armados para tomar el poder. Por ello cuando, el 6 de enero de 1892, funda el Partido Revolucionario Cubano sus Bases estatutarias contienen el plan estratégico sobre el que argumenta su propaganda. Allí, uno de los temas más reiterados es conseguir la unión de todos los cubanos, cualquiera que sea su origen y tendencias, en un proyecto común, sin distinción, ni reservas, de clases ni de razas.

Este último aspecto, la distinción entre razas y su posible enfrentamiento, es otro de los problemas que Martí quiere solucionar, ya que vela un cierto riesgo, para el triunfo en la guerra que preparaba la diversa composición racial del pueblo cubano. Muchas veces trató esta cuestión, la más definitoria fue en un ensayo, publicado en Patria el 16 de abril de 1893, que titula Mi Raza, donde deja muy claro que "en Cuba no hay temor alguno a la guerra de razas (...) Cubano es más que blanco, más que mulato, más que negro. (...). En Cuba no habrá nunca guerra de razas. (...). En Cuba hay mucha grandeza, en negros y blancos". La técnica propagandística de la repetición queda patente de forma clara en el texto mencionado.

Técnica a la que, en su esfuerzo permanente de alcanzar la unión para la acción revolucionaria, también recurre al preparar sus discursos. Ejemplo antológico entre ellos es el que pronuncia en el Liceo Cubano de Tampa, el 26 de noviembre de 1891, en el que la persuasión, fin inmediato de todo propagandista es sólo superada por la elocuencia, por el convencimiento de que lo predicado es " para el bien y prosperidad de todos los cubanos"; así al presentar los temores que podrían argumentar aquellos que intentasen desmoralizar a los independentistas, desmonta con brillantez cada argumento y los va cerrando uno a uno con un rotundo "i Mienten !" para finalizar el discurso con un rotundo eslogan " y pongamos alrededor de la estrella, en la bandera nueva, esta fórmula de amor triunfante: 'Con todos y para el bien de todos"'.

En el segundo frente, dirigido a los españoles, utiliza la propaganda de división tratando fundamentalmente de restar al gobierno de España el apoyo popular, no sólo de los cubanos sino de los españoles en el conflicto planteado, antes y durante la guerra. Así, en mayo de 1892 en carta dirigida al presidente del Club " José María Heredia" de Kingston: "El partido quiere preparar la guerra y preparar la República, derrotar a España y valerse para ello de los mismos españoles liberales y útiles".

Mensaje que repetirá en el Manifiesto de Montecristi al afirmar que "la guerra no es contra el español, que, en el seguro de sus hijos y en el acatamiento a la patria que se ganen, podrá gozar, respetado y aún amado, de la libertad...". Incluso, una vez iniciado el conflicto, recordará a los jefes militares, en una circular fechada el 28 de abril de 1895 en el Cuartel General del Ejército Libertador que: "La guerra debe ser sinceramente generosa, libre de todo acto de violencia innecesaria contra personas y propiedades, y de toda demostración o indicación de odio al español... sólo ha de ser inexorable contra el enemigo, español o cubano, que preste servicio activo contra la Revoluciono Al español neutral se le tratará con benignidad(...) a los soldados quintos se tratará de atraerlos, a los prisioneros se les devolverá vivos y agradecidos..." 
En el exterior, el tercer frente, busca obtener no sólo la connivencia, sino también "la simpatía pública" con su proyecto de determinados pueblos. En especial de los países de habla hispana y en particular del pueblo en el que la mayoría de los emigrados viven; pues, a juicio de Martí, la revolución correrla grave riesgo sino se lograse mover la consideración del pueblo y gobierno de los Estados Unidos. Por ello, según escribe el 13 de mayo de 1892 al Cuerpo de Consejo de Key West, se propone atender ese objetivo "por medio de un Manifiesto en lengua inglesa que a la vez explique el carácter real de nuestro país y la razón inevitable de nuestras luchas, a cuya publicación, distribuida en los centros de influjo en el Norte, seguirán otras especiales que la mantengan presente y una labor continua en la prensa inglesa de dignificación y propaganda".

Propaganda hacia el exterior que no cesa de explicar que Cuba ha alcanzado la madurez para autogobernarse y, que la emancipación del país será "para bien de América y del mundo", puesto que "la guerra de independencia de Cuba, nudo del haz de islas donde se ha de cruzar, en el plazo de pocos años, el comercio de los continentes, es suceso de gran alcance humano, y servicio oportuno que el heroísmo juicioso de las Antillas presta (....) al equilibrio aún vacilante del mundo".

No deja nada al azar. Pues una vez iniciado el levantamiento con el Grito de Baire, y preparando su desembarco en Cuba, escribe, el 26 de febrero de 1895, al secretario del Partido Revolucionario Cubano, sobre los ejes futuros de la propaganda en Patria: resaltar la importancia que ha tenido el Partido para unir las distintas tendencias de los grupos emigrados, insistir en que no deben repetirse las divisiones y errores del pasado y, por último, buscar el apoyo de los españoles de la Isla, indicando que se debe afirmar" alto y vibrante, que la revolución aspira a dejar en sus casas a los españoles respetuosos y productores: la caterva ladrona se irá sola, y los españoles nos ayudarán a quitarnos la lepra, que irá al mar en cuanto no tenga que roer; pero en el país, como nuestros, como hombres respetados y útiles, los que nos respetan: esto es catecismo".

\section{EFICACIA DE LA PROPAGANDA}

Puede afirmarse que la actividad propagandista tuvo éxito no sólo por su perseverancia sino por sus actitudes. Pues como afirmó Julio Burell, el 26 de mayo de 1895, "juntaba en su persona funesta las artes para la conjura y el espíritu de sugestión. Con su política de perseverancia y de insinuación (...) iba Martí de uno a otro lado, animando a los tímidos, fortaleciendo a los vacilantes, prometiendo a los codiciosos, siempre sembrando su odio a España".

Su acción para conseguir la unión de los diversos grupos- separatistas cubanos fructificó, al menos hasta su muerte. Más tarde, cuando vuelven a aparecer disensiones entre aquellos durante la guerra y después de ella, y que alcanzan tal gravedad que obligan a los Norteamericanos a intervenir en la Isla en 1907, se le añora; así puede deducirse de las palabras del, entonces, embajador cubano en Wáshington, Gonzalo de Quesada: "La única salvación que tenemos es la predicación de la armonía y el amor con que una vez movió al mundo el maestro Martí. Si las 
pasiones, los enconos y las ambiciones hacen imposible la unión y la armonía, la hora de nuestra desaparición ha llegado".

También logra que el apoyo popular a los rebeldes en la Isla sea mayor que en levantamientos anteriores, restándoselo a la causa de España. Así parece quedar reconocido cuando en mayo de 1895 Martínez Campos, un mes después de hacerse cargo de la Capitanía General de Cuba, escribe a Canovas, jefe de Gobierno: "Los pocos españoles que hay en la isla sólo se atreven a proclamarse como tales en las ciudades. El resto de los habitantes odia a España (...). Hasta los tímidos están prontos a seguir las órdenes de los caciques insurrectos".

El éxito de su acción en el frente exterior es claro. En España Castelar, en septiembre de 1895 en un artículo titulado La insurrección cubana y los periódicos extranjeros, se pregunta los motivos por los qué la mayoría de la prensa extranjera se habla puesto al lado de la insurrección, cuando la prensa española había apoyado todo lo que fuese hecho en el mundo en bien de la democracia y a favor de los Derechos Humanos. No entiende Castelar, cómo países como Gran Bretaña, Francia, Italia o Bélgica, que tienen posesiones tan alejadas de la Metrópoli como Cuba para España, no apoyan la presencia española en la Isla y dejen que se pierda no sólo para España sino también para Europa, ya que era tan imprescindible para mantener la hegemonía europea en aquella parte del mundo como lo hablan sido otras islas en el pasado para otros imperios.

Hasta los Norteamericanos parecen hacerse eco de las palabras de Martí en la resolución conjunta aprobada por la Cámara de Representantes y el Senado, el 18 de abril de 1898, en la que se exige que el Gobierno español renuncie a la Isla considerando "que el odioso estado de cosas que ha existido en Cuba durante los tres últimos años (...) ha sido un destrozo para la civilización cristiana".

La muerte de Martí, el 19 de mayo de 1895, va a dejar su obra política inacabada. En adelante continuarán las operaciones militares en Cuba pero nadie será capaz de sustituirlo en la labor de propaganda, porque como en otros grandes propagandistas tiene su impronta personal y muere con él.

\section{BIBLIOGRAFÍA}

Martí, J. (1963-1973): O. C. La Habana. Nacional de Cuba.

Lizaso, F. (1930-31): Epistolario de José Martí. La Habana. Editorial Cultural.

Martínez Estrada, E. (1966): Martí, el héroe y su acción revolucionaría. México. Siglo XXI Editores.

Casa de las Américas (1974): Martí revolucionario, (2a edición). La Habana. 
Fernández Almagro, M. (1974): Historia Política de la España Contemporánea. (3a edición). Madrid. Alianza Editorial.

Diario de Cádiz: mayo a octubre de 1895.

\section{Francisco Marín Calahorro}

Coronel de Caballería en la Oficina de Relaciones Informativas de Defensa. Licenciado en Derecho y Doctor en Ciencias de la Información con la Tesis "Comunicación social y situaciones de crisis internacionales". 